\title{
SOCIEDAD DEL CONOCIMIENTO Y EDUCACIÓN XXXI SITE-UNED-PLASENCIA-NOVIEMBRE DE 2012
}

La información, la comunicación, la educación y el conocimiento son esenciales para la iniciativa, el progreso y el bienestar de las sociedades. A su vez, las tecnologías de la información y la comunicación (TIC) que potencian esos cuatro conceptos tienen inmensas repercusiones en prácticamente todas las dimensiones de nuestras vidas. La capacidad de las tecnologías digitales para superar o, en todo caso, reducir las consecuencias de muchos obstáculos tradicionales, especialmente los que suponen el tiempo y la distancia, ha propiciado que, por primera vez en la historia, el vasto potencial de estas tecnologías sea utilizado por millones de personas en todo el mundo y en beneficio de ellas y de la sociedad.

Nos encontramos en la sociedad de la información, en la sociedad red, en la sociedad del aprendizaje, en la sociedad del conocimiento. Bien sabemos que a través de la información surge el conocimiento, una vez que aquélla ha dado significado a los datos, con el apoyo inexcusable de la educación, de las experiencias previas y de los valores asumidos. Cierto que el conocimiento se produce por una confluencia, entre otros, de dos factores sustanciales, la indicada información (búsqueda, procesamiento, almacenamiento...) y la comunicación (distribución e intercambio de información). Y esos procesos se activan de forma sistemática a través de la educación para lo que entendemos que se hace preciso el uso adecuado de los recursos, herramientas, aplicaciones, redes y entornos tecnológicos que configuran elementos esenciales de esta sociedad.

Pero esas posibilidades no son universales, no todos disponen de ellas. Existe la brecha digital. Pero no sólo esa brecha a la que habitualmente se alude, la referida a las posibilidades de acceso o no a las tecnologías digitales. Existen otras brechas, digitales también, en las sociedades desarrolladas. Por ejemplo, en el campo que nos ocupa, la brecha generacional con implicaciones, sin duda, en los centros educativos y aquella existente entre los ciudadanos que usan estas tecnologías de forma adecuada y aquellos otros que aun disponiendo de ellas o pudiendo acceder a las mismas sin grave dificultad, no lo hacen o no las usan adecuadamente. En este último caso la escuela tiene un buen reto por delante.

Bien sabemos que en los países desarrollados nuestros niños, adolescentes y jóvenes viven en la red o, al menos, rodeados de artefactos y artilugios digitales. Sería de desear que en todos los países e instalaciones educativas (muchos están lejos de lograrlo) nuestros niños y adolescentes finalizasen sus estudios de enseñanza primaria, cuánto más de la secundaria, plenamente alfabetizados en todo lo que suponen los nuevos códigos tecnológicos e informacionales de los sistemas digitales, cada vez más necesarios. 
Parece que en ciertos sectores del ámbito educativo aún se sigue discutiendo sobre la utilidad de las tecnologías digitales, para que éstas sean integradas plenamente en las estrategias de enseñanza y en los procesos de aprendizaje en nuestros centros educativos. Mal nos irá si la educación se aísla, aún más, de lo que sucede en el entorno exterior al aula. La realidad exterior está inundada de lo digital. El presente y cuánto más el futuro son digitales, ¿cómo preparar a los ciudadanos del futuro si se ignora desde la escuela esta realidad? Cada vez el porcentaje de aprendizaje realizado fuera de los muros del recinto escolar se irá incrementando y así la escuela tradicional, si no rectifica, irá cavando su propia tumba. Resulta paradójico que organizaciones sociales que surgieron para la generación de aprendizajes sean tan lentas aprendiendo o, en el peor de los casos, se nieguen a aprender. Y esto no es de ahora. Cualquier innovación pedagógica ha tardado decenas de años en asentarse en las aulas.

Pero supongamos que ahora queremos que no suceda así. Ese intento de reducir esas otras brechas digitales antes aludidas fructificará en estos entornos escolares si se cuenta con docentes dispuestos y capacitados para hacerlo, para trabajar de otra manera, con otros métodos, con otros recursos. Resultará, como siempre, muy difícil porque la estructura actual de la escuela se basa generalmente en una concepción de relación vertical bastante rígida y obsesionada (u obligada) con cumplir a rajatabla las exigencias marcadas en los programas curriculares redactados por las administraciones públicas. Y lo digital se contrapone a todas esas rigideces. Haría falta no sólo capacitación y disposición de los docentes, también flexibilidad de las directrices de la administración educativa y cambios en las políticas educativas. Estas tecnologías rompen las coordenadas tempo-espaciales, rompen el esquema tradicional de grupo de edad en el aula, los recursos son otros y la evaluación habría de adecuarse. Nuevos métodos para una nueva concepción educativa.

Pero ¿cómo suponemos que deberían ser estos cambios?, ¿superficiales, sólo cuantitativos o cualitativos, estructurales, radicales...? Más allá de que las finalidades educativas y muchos de los principios pedagógicos siguen vigentes, las formas, el espacio, el tiempo, los recursos, las relaciones verticales y horizontales, etc., como decimos, se presentan como mucho más flexibles, elásticos, porosos y maleables.

La conectividad, la interacción, la hipertextualidad, el hipermedia, están cambiando, tienen que cambiar profundamente la idea de escuela, la concepción del aula física, del recinto escolar y, naturalmente, del hacer de los docentes y del aprender de los alumnos. La escuela tiene que mediar para que la ingente información que llega pueda, una vez procesada, ordenada y bien seleccionada, convertirse en conocimiento.

Toda esta problemática y mucha más fue abordada en el XXXI Seminario Interuniversitario de Teoría de la Educación (SITE) que se desarrolló del 11 al 14 de noviembre de 2012 en la extremeña ciudad de Plasencia, organizado por la UNED. 
En este SITE, además de disfrutar de una interesante visita guiada a la ciudad histórica de Plasencia y a su hermosa catedral, coincidiendo con las celebraciones en torno al 40 Aniversario de la UNED, se aprovechó desde el propio SITE para celebrar una mesa redonda en el Centro Asociado de la UNED en Plasencia, sobre el tema 40 años de Educación Universitaria a Distancia en España, en la que participaron los profesores Jaume Sarramona y quien redacta estas líneas.

La actividad académica más intensa giró, como viene siendo habitual en los SITE, en torno a las cuatro ponencias marco que lo configuran y que en su XXXI edición, en el marco del Parador Nacional de Plasencia, se conformaron de la siguiente manera:

Ponencia I. Sociedad del conocimiento. Perspectiva pedagógica. Ana Ayuste, Universidad de Barcelona (coordinadora); Begoña Gros Universidad de Barcelona; Sofía Valdivielso, Universidad de Las Palmas.

Ponencia II. Web 2.0 y redes sociales. Implicaciones educativas. Miguel Ángel Santos Rego, Universidad de Santiago (coordinador); Félix Etxeberría, Universidad del País Vasco; Mar Lorenzo, Universidad de Santiago de Compostela; Enric Prats, Universidad de Barcelona.

Ponencia III. Las competencias de los profesionales de la educación hoy. La transformación de la práctica educativa. José M. a Asensio, Universidad Autónoma de Barcelona (coordinador); Isabel Álvarez, Universidad Autónoma de Barcelona; Felipe Vega, Universidad de Málaga; Teófilo Rodríguez Neira, Universidad de Oviedo.

Ponencia IV. Nuevos modos de aprendizaje en el contexto de la Sociedad del Conocimiento. Joaquín García Carrasco, Universidad de Salamanca (coordinador); Bernardo Gargallo López, Universidad de Valencia; Francesc Sánchez i Peris, Universidad de Valencia; Andrés García Manzano, IES "La Vaguada”, Zamora.

A las cuatro ponencias se les sumaron doce adendas a la primera de ellas firmadas por un total de veintiún docentes, seis a la segunda firmadas por ocho miembros, catorce a la tercera firmadas por veintitrés y cinco a la cuarta que firmaron otros cinco profesores.

Desde la UNED se preparó la edición de un libro bajo el título general del propio sITE, Sociedad del conocimiento y educación. Este libro se editó en formato impreso bajo la siguiente referencia: GARCía ARETIO, L. (ed.) Sociedad del conocimiento y educación. Madrid, UNED, 2012. Y también en formato electrónico donde se puede acceder libremente desde http://goo.gl/VMued. 